\title{
An Automatic Course Assessment Tool for Weakness Identification
}

\author{
Chunlei Liu \\ Department of Mathematics and Computer Science \\ Valdosta State University \\ Valdosta, GA 31698, USA \\ cliu@valdosta.edu
}

\author{
Li-Mei Chen \\ Department of English \\ Valdosta State University \\ Valdosta, GA 31698, USA \\ lchen@valdosta.edu
}

\begin{abstract}
We develop an automatic course assessment tool that gives numerical indicators on fulfilling course learning outcomes and identifies course weaknesses for future improvement. Four years of application indicate that this tool is very effective in revealing course weaknesses and in reducing the time spent on course assessment.
\end{abstract}

Keywords-Assessment; Accreditation; Weakness Identification

\section{INTRODUCTION}

Course assessment is an important requirement for accreditation but is very time-consuming. Besides teaching the courses in classroom or online, faculty have to spent significant time to collect and analyze student data to meet program assessment and accreditation requirements. While many accreditation agents have their requirements on course assessment and continuous improvement, they usually gave little instruction on how to collect assessment samples, analyze student data and find areas for future improvement. In the literature, there are very few quantitative methods that can be used for automatic, large-scale assessment

In our recent preparation for ABET accreditation [1], we follow the Faculty Course Assessment Report (FCAR) process [2], which is also adopted by many other universities [3, 4, 5], to assess our program and courses. At the beginning of the semester, the course instructor receives clarifications and training and agrees on the FCAR completion date ( 2 weeks after the semester ends). The instructor keeps record of evaluation data during the semester, and writes an FCAR to assess the course and to identify existing problems. In the beginning of the following semester, the computer science faculty analyzes the previous semester FCARs and agrees on a set of actions. When the course is offered next time, the instructor who teaches this course will review the FCAR and take the agreed actions in the course to improve it.

The core of the assessment in FCAR is to use two vectors: EEMU (Excellent, Effective, Minimal, and Unsatisfactory) and EPAN (Exemplary, Proficient, Apprentice, and Novice) to determine whether each course learning outcome or program outcome is successfully met. None of the references specifies the method to determine a student's proficiency in EEMU rating and ability in EPAN rating. In our earlier assessment cycles, many instructors had to check each student's performance in the homework, projects and tests to make a subjective estimate to determine whether the student achievement in the course learning outcome is excellent, effective, minimal, or unsatisfactory; or exemplary, proficient, apprentice, or novice in the program learning outcome. Such comprehensive and subjective estimation was ambiguous, time-consuming and yielded inaccurate and inconsistent results Some instructors estimated the students' achievement from their acquaintance with the students; others said they had to come up with numbers that might be inaccurate. A more severe problem emerged when we compared the assessment results across different courses. Since each instructor estimated his or her EEMU and EPAN vectors differently, the results from different courses were completely inconsistent and incomparable.

Through comparison and experiment, we developed a selective and objective method that calculates the assessment results quantitatively. We designed a set of spreadsheets to collect student performance data, to calculate the assessment results automatically, and to identify areas for future improvement.

In this paper, we share our selective and objective assessment method and the way to automatically identify weaknesses in the course in Section 2 and 3. The Excel spreadsheets are introduced in Section 4. Even though this method is designed for ABET accreditation of our computer science program, it can be used in accreditations and assessment for all disciplines.

\section{ASSESSMENT COMPUTATION}

After using the FCAR procedures for one semester, our faculty found that the comprehensive and subjective method to determine the EEMU and EPAN vectors is time-consuming, inaccurate and inconsistent, and will be indefensible in future ABET interviews. The CS faculty asked for an accurate but less time-consuming method. So, we decided to design a selective and objective method for calculating the EEMU and EPAN vectors. In this method, a small set (usually three to four) of core and typical questions for each learning outcome is selected to conduct the assessment, and student scores are used to determine these EEMU and EPAN vectors. We also think that the vectors should reflect the proficiency and ability of students who passed the course, not those who failed and need to repeat. In all courses in our CS program, a student has to get 
a $\mathrm{C}$ or better to pass a course, so our calculations are based on students whose final grade is A, B, or C. Students whose final grades are D, F, W or I are excluded. We set the thresholds for Excellent, Effective, and Minimal levels as 90\%, $75 \%$ and $60 \%$ respectively, and total below $60 \%$ is Unsatisfactory, same as in [6]. The same thresholds are also used for the EPAN vector.

The following are steps to calculate the EEMU and EPAN vectors.

1. Identify a set of typical questions that assess the course learning outcome (for EEMU) or a program outcome (for EPAN).

2. Enter student scores on these questions for students whose final grade is $\mathrm{A}, \mathrm{B}$ or $\mathrm{C}$.

3. Calculate the weighted average percentage on the selected set of questions. Weights are set according to their percentage in the course grading scale.

4. Use the average percentage to determine how many students fall into the EEMU or EPAN categories using the preselected $90 \%, 75 \%$ and $60 \%$ thresholds.

\section{WEAKNESS IDENTIFICATION}

An important goal of assessment is to determine whether the learning outcomes are successfully met so that problematic areas can be identified for future improvement. In the literature, we did not find any widely-accepted criterion to make such determination in the literature. After some calculations and experiments, we established the following assessment criteria:

The average EEMU or EPAN rating will be 1.5 or greater. No more than $20 \%$ will receive the rating of Unsatisfactory or Novice.

The purpose of the criteria has two aspects. The average rating represents the overall student performance. An average rating lower than 1.5 means the majority of students have not achieved this learning outcome. Revising the teaching approach or spending more time on related topics, for example, can help to improve the average.

An Unsatisfactory or Novice rating of $20 \%$ or higher means the students' learning on this learning outcome is very uneven. Individual conference or homework comments for the weak students, for example, can help to reduce the Unsatisfactory or Novice rating.

The following are steps to identify the learning outcomes that are not attained.

1. The Average Rating is a weighted average based on the number on scale:

$$
\frac{3 \times \text { Excellent }+2 \times \text { Effective }+1 \times \text { Minimum }}{\text { Excellent }+ \text { Effective }+ \text { Minimum }+ \text { Unsatifactory }}
$$

or

$\underline{3 \times \text { Exemplary }+2 \times \text { Proficient }+1 \times \text { Apprentice }}$

Exemplary+Proficient+Apprentice+Novice
2. Calculate the Percentage of Unsatisfactory or the Percentage of Novice as

$$
\frac{\text { Unsatifactory }}{\text { Excellent+Effective+Minimum+Unsatifactory }} \times 100 \%
$$

or

$$
\frac{\text { Novice }}{\text { Exemplary+Proficient+Apprentice+Novice }} \times 100 \%
$$

3. If the Average Rating is 1.5 or greater and the Percentage of Unsatisfactory or the Percentage of Novice is $20 \%$ or smaller, then the Course Learning Outcome or the Program Outcome is successfully met. Otherwise, it is not met.

\section{SPREADSHEET AUTOMATION}

To automate the assessment work, we designed several Excel spreadsheets to collect course data and to perform the described assessment calculation. Fig. 1 shows an example spreadsheet for entering student per-question scores for selected questions. The questions are arranged according to exams or projects for easier data input. Because of space limitation, only a few students' data are displayed in the screen shots.

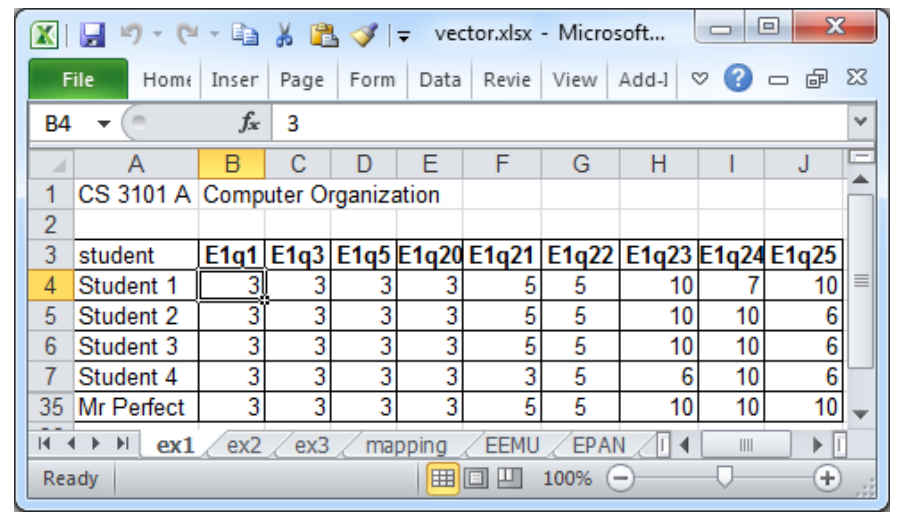

Fig. 1. A data entry spreadsheet

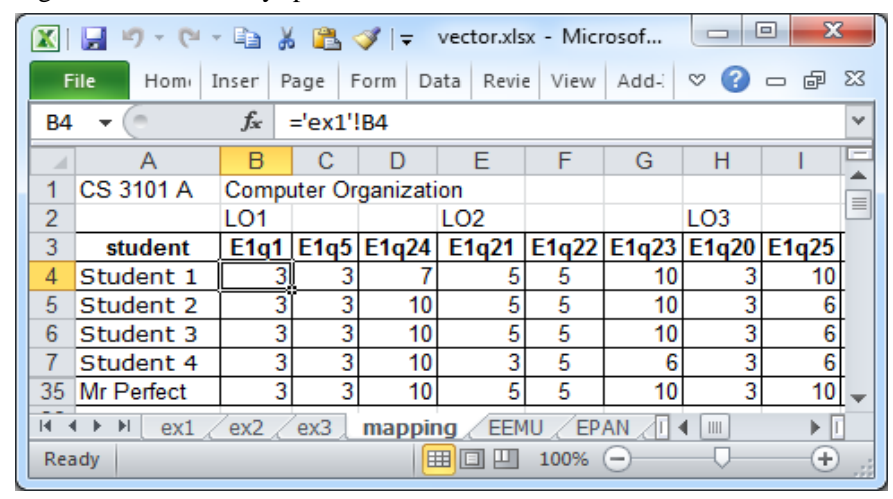

Fig. 2. Learning objective to question mapping 
A mapping table, as shown in Fig. 2, maps each learning outcome to the selected test questions. Each column represents the test score data. Cells in the mapping table contain links to the test score spreadsheets. When the instructor finishes entering the test scores, the scores will appear on this mapping spreadsheet. The entering and mapping spreadsheets are designed to reduce the work because some questions may be used by more than one learning outcome, and the selected questions may not be in a convenient order for data entry.

The last two spreadsheets, as shown in Fig.s 3 and 4, calculate the EEMU and EPAN vectors. Test scores selected for a learning outcome are combined to calculate a percentage and then translated to a scale $3,2,1$ or 0 . If a students did not pass the course (with a grade of D or worst), the scale is simply a blank. At the bottom of these two spreadsheets, the numbers of scales 3,2,1,0 are aggregated to find the numbers for EEMU and for EPAN. The percentages of Unsatisfactory and Novice are also calculated.

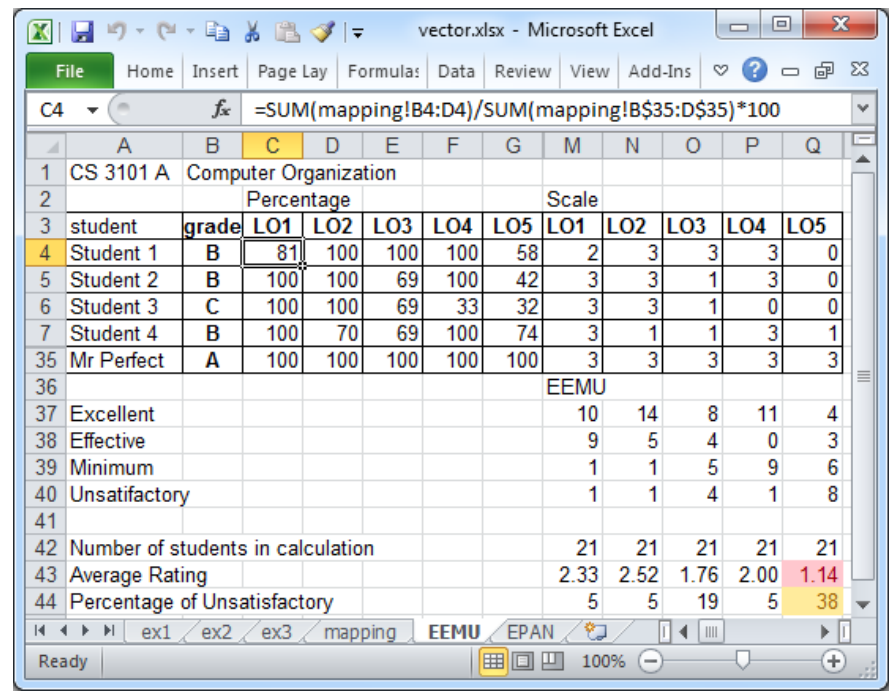

\section{Fig. 3. EEMU calculation}

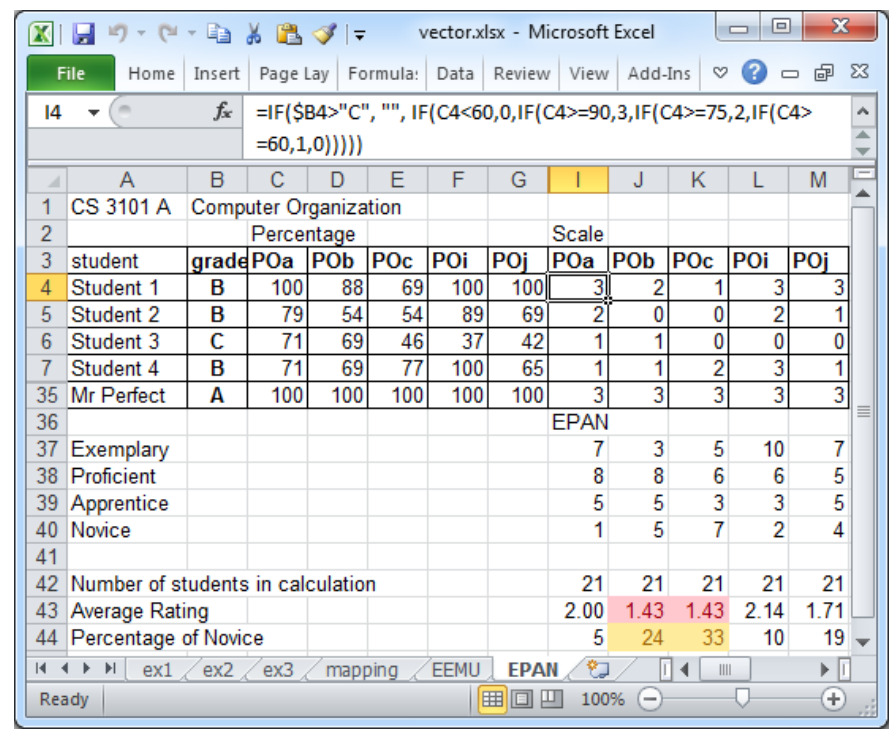

Fig. 4. EPAN calculation
The EEMU and EPAN spreadsheets also contain a conditional highlighting feature to automatically identify weaknesses in attaining the course learning outcomes and program outcomes. Any average rating below 1.5 will trigger a dark red highlight and any percentage of Unsatisfactory or Novice will trigger a dark yellow highlight. This feature allows the instructor to find out which learning outcomes or program outcomes are not attained. A red highlight indicates that the outcome is not well achieved by the majority of the class; revising the teaching approach or spending more time on related topics can help to improve the class average. A yellow highlight indicates that the outcome is missed by a part of the class, Individual conference or homework comments for the weak students are appropriate.

In the example shown in the screen shots, Learning Outcome 1 is fully attained, but Learning Outcome 5 and Program Outcomes b and c are not attained.

\section{ASSESSMENT RESUlts}

This tool has been used in the assessment of our Computer Science courses since spring 2011. As an example, the assessment result of CS 3101 Computer Organization is shown in Table 1. The red and yellow highlights reveal that LO3, 5, 6 and 8 are the major weaknesses in this course. Table 2 shows the number of courses in which each program outcome is covered, the number of courses attaining the program outcome, and the percentage of attainment. The percentage of attainment reveals that $\mathrm{PO} \mathrm{b}$ is the weakness that needs improvement.

In summary, this tool is very effective in reducing the time spent on course assessment while giving numerical indicators on fulfilling each course learning outcome and program outcome. The criteria are appropriate in identifying course weaknesses, where faculty can focus on in future improvement.

\section{ACKNOWLEDGMENT}

This research is supported in part by the Valdosta State University IDEA Center Pedagogical Innovations Grant and the Faculty Research Seed Grant.

\section{REFERENCES}

[1] Computing Accreditation Commission, "Criteria for Accrediting Computing Programs, 2015-2016”, http://www.abet.org.

[2] J. Estell, "Faculty Course Assessment Report (FCAR) Instructions," Best Assessment Processes VI, Rose-Hulman Institute of Technology, 2004.

[3] B. R. Maxim," "Closing the Loop: Assessment and Accreditation", Journal of Computing Sciences in Colleges, vol. 20 issue 1, 2004.

[4] B. Thomas, "The Quest for Outcome Assessment: The Faculty Course Assessment Reports", 2005 ASEE Southeast Section Conference, University of Tennessee at Chattanooga, Chattanooga, Tennessee, 2005.

[5] M. Faiz, et al, "Using Faculty Course Assessment Report for the Assessment of an Associate Degree Course in Engineering Technology program", 6th Conference on Engineering Education (ICEED), pp.73-78, 2014.

[6] J. Estell, 2006, "Streaming the Assessment Process with the Faculty Course Assessment Report", Proceedings of the Best Assessment Processes IX Symposium, Rose-Hulman Institute of Technology, 2006. 
TABLE I. ATTAINMENT OF CS 3101 COURSE LEARNING OUTCOMES FROM FALL 2011 TO SPRING 2015

\begin{tabular}{|c|r|r|r|r|r|r|r|r|r|}
\hline Semester & LO1 & LO2 & LO3 & LO4 & LO5 & LO6 & LO7 & LO8 & LO9 \\
\hline \multicolumn{8}{|c|}{ Average of EEMU } \\
\hline Fall 2011 & 2 & 2.21 & 2.14 & 2 & 1.5 & 1.5 & 1.71 & 1.71 & 1.64 \\
\hline Spring 2012 & 1.94 & 2.13 & 1.06 & 1.81 & 0.63 & 1.06 & 2.06 & 1.44 & 1.81 \\
\hline Fall 2012 & 1.89 & 1.79 & 1.37 & 2.26 & 1.58 & 2.26 & 2.21 & 1.32 & 1.53 \\
\hline Spring 2013 & 2.88 & 2.24 & 2.94 & 1.88 & 2.35 & 1.71 & 2.18 & 1.76 & 1.59 \\
\hline Fall 2013 & 1.95 & 2.25 & 0.95 & 2.2 & 1.25 & 1.35 & 1.9 & 0.8 & 1.75 \\
\hline Spring 2014 & 2.33 & 2.52 & 1.76 & 2 & 1.14 & 1.62 & 2.24 & 1.14 & 1.76 \\
\hline Fall 2014 & 2.4 & 2.05 & 1.7 & 1.85 & 1.1 & 1.65 & 1.65 & 1.45 & 2 \\
\hline Spring 2015 & 1.84 & 2.58 & 1.47 & 1.68 & 0.95 & 1.16 & 2.11 & 0.89 & 1.63 \\
\hline \multicolumn{8}{|c|}{ Percentage of Unsatisfactory } \\
\hline Fall 2011 & 21 & 7 & 29 & 7 & 36 & 36 & 7 & 29 & 21 \\
\hline Spring 2012 & 25 & 6 & 25 & 19 & 56 & 44 & 13 & 13 & 6 \\
\hline Fall 2012 & 21 & 32 & 42 & 0 & 21 & 11 & 5 & 32 & 26 \\
\hline Spring 2013 & 0 & 18 & 0 & 12 & 0 & 18 & 18 & 6 & 24 \\
\hline Fall 2013 & 25 & 10 & 50 & 10 & 40 & 40 & 10 & 40 & 10 \\
\hline Spring 2014 & 5 & 5 & 19 & 5 & 38 & 29 & 10 & 24 & 19 \\
\hline Fall 2014 & 10 & 5 & 25 & 15 & 40 & 35 & 20 & 35 & 15 \\
\hline Spring 2015 & 16 & 0 & 26 & 5 & 53 & 2.11 & 0 & 42 & 16 \\
\hline
\end{tabular}

TABLE II. ATtAINMENT OF PROGRAM OUTCOMES FROM FALL 2011 TO SPRING 2015

\begin{tabular}{|c|c|c|c|c|c|c|c|c|c|c|c|c|}
\hline Semester & PO & $\mathbf{a}$ & b & c & d & e & f & g & h & $\mathbf{i}$ & $\mathbf{j}$ & $\mathbf{k}$ \\
\hline \multirow{3}{*}{ Fall 2011} & coverage & 11 & 11 & 12 & 3 & 2 & 3 & 2 & 3 & 12 & 14 & 11 \\
\hline & PO attained & 8 & 8 & 12 & 3 & 2 & 3 & 2 & 3 & 9 & 11 & 8 \\
\hline & $\%$ attained & 72 & 72 & 100 & 100 & 100 & 100 & 100 & 100 & 75 & 78 & 72 \\
\hline \multirow{3}{*}{ Spring 2012} & coverage & 10 & 11 & 10 & 3 & 5 & 4 & 2 & 3 & 11 & 11 & 9 \\
\hline & PO attained & 5 & 7 & 8 & 3 & 5 & 4 & 1 & 2 & 8 & 9 & 7 \\
\hline & $\%$ attained & 50 & 63 & 80 & 100 & 100 & 100 & 50 & 67 & 72 & 81 & 78 \\
\hline \multirow{3}{*}{ Fall 2012} & coverage & 10 & 11 & 9 & 3 & 3 & 3 & 2 & 3 & 10 & 12 & 9 \\
\hline & PO attained & 7 & 7 & 5 & 3 & 3 & 3 & 2 & 3 & 6 & 7 & 6 \\
\hline & $\%$ attained & 70 & 63 & 55 & 100 & 100 & 100 & 100 & 100 & 60 & 58 & 67 \\
\hline \multirow{3}{*}{ Spring 2013} & coverage & 10 & 11 & 10 & 2 & 3 & 3 & 1 & 2 & 8 & 11 & 10 \\
\hline & PO attained & 9 & 7 & 7 & 2 & 3 & 3 & 1 & 2 & 6 & 9 & 7 \\
\hline & $\%$ attained & 90 & 63 & 70 & 100 & 100 & 100 & 100 & 100 & 75 & 81 & 70 \\
\hline \multirow{3}{*}{ Fall 2013} & coverage & 12 & 11 & 12 & 4 & 3 & 3 & 3 & 4 & 10 & 11 & 10 \\
\hline & PO attained & 9 & 6 & 9 & 4 & 3 & 3 & 2 & 3 & 9 & 9 & 8 \\
\hline & $\%$ attained & 75 & 55 & 75 & 100 & 100 & 100 & 67 & 75 & 90 & 82 & 80 \\
\hline \multirow{3}{*}{ Spring 2014} & coverage & 12 & 13 & 13 & 3 & 2 & 4 & 1 & 4 & 11 & 14 & 13 \\
\hline & PO attained & 9 & 9 & 9 & 3 & 1 & 4 & 1 & 2 & 9 & 10 & 11 \\
\hline & $\%$ attained & 75 & 69 & 69 & 100 & 50 & 100 & 100 & 50 & 82 & 71 & 85 \\
\hline \multirow{3}{*}{ Fall 2014} & coverage & 10 & 11 & 9 & 2 & 1 & 2 & 1 & 1 & 6 & 11 & 10 \\
\hline & PO attained & 8 & 9 & 8 & 2 & 1 & 2 & 1 & 1 & 4 & 8 & 7 \\
\hline & $\%$ attained & 80 & 82 & 89 & 100 & 100 & 100 & 100 & 100 & 67 & 73 & 70 \\
\hline \multirow{3}{*}{ Spring 2015} & coverage & 11 & 12 & 12 & 3 & 2 & 4 & 1 & 4 & 11 & 12 & 12 \\
\hline & PO attained & 7 & 7 & 9 & 3 & 2 & 4 & 1 & 4 & 8 & 9 & 9 \\
\hline & $\%$ attained & 64 & 58 & 75 & 100 & 100 & 100 & 100 & 100 & 73 & 75 & 75 \\
\hline
\end{tabular}

